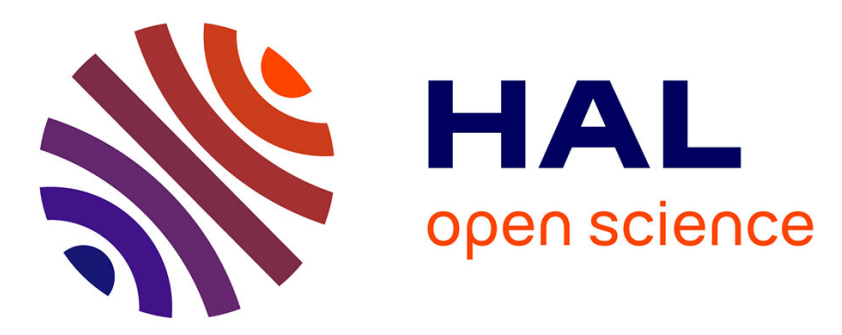

\title{
Observation of a magnetic state in the organic superconductor (TMTSF) 2ClO4: influence of the cooling rate
}

\author{
T. Takahashi, D. Jérome, K. Bechgaard
}

\section{- To cite this version:}

T. Takahashi, D. Jérome, K. Bechgaard. Observation of a magnetic state in the organic superconductor (TMTSF) 2ClO4: influence of the cooling rate. Journal de Physique Lettres, 1982, 43 (15), pp.565573. 10.1051/jphyslet:019820043015056500 . jpa-00232093

\section{HAL Id: jpa-00232093 https://hal.science/jpa-00232093}

Submitted on 1 Jan 1982

HAL is a multi-disciplinary open access archive for the deposit and dissemination of scientific research documents, whether they are published or not. The documents may come from teaching and research institutions in France or abroad, or from public or private research centers.
L'archive ouverte pluridisciplinaire HAL, est destinée au dépôt et à la diffusion de documents scientifiques de niveau recherche, publiés ou non, émanant des établissements d'enseignement et de recherche français ou étrangers, des laboratoires publics ou privés. 
Classification

Physics Abstracts

$76.60-75.50$

\title{
Observation of a magnetic state in the organic superconductor (TMTSF) $\left.)_{2} \mathrm{ClO}_{4}{ }^{*}\right)$ : influence of the cooling rate
}

\author{
T. Takahashi, D. Jérome and K. Bechgaard (**) \\ Laboratoire de Physique des Solides, Université de Paris-Sud, 91405 Orsay, France
}

(Reçu le 15 mars 1982, révisé le 8 juin, accepté le 15 juin 1982)

\begin{abstract}
Résumé. - L'apparition d'une phase magnétique est observée en dessous de $3,5 \mathrm{~K}$ environ juste au-dessus de la transition supraconductrice $\left(T_{\mathrm{c}} \approx 1 \mathrm{~K}\right)$ dans $(\mathrm{TMTSF})_{2} \mathrm{ClO}_{4}$. L'état magnétique obtenu après un refroidissement rapide $(\approx 25 \mathrm{~K} / \mathrm{min}$.) a été caractérisé par des mesures de l'amplitude et de temps de relaxation de la résonance nucléaire de ${ }^{77} \mathrm{Se}$ et ${ }^{1} \mathrm{H}$. La température d'ordre magnétique ne dépend pratiquement pas du champ magnétique entre 10 et $65 \mathrm{kOe}$. Dans le même échantillon refroidi lentement l'ordre magnétique n'est plus observé au-dessus de 1,3 K. Les effets de cyclages thermiques sont parfaitement reproductibles. Ces résultats suggèrent l'existence d'un désordre du réseau à basse température gelé par le refroidissement rapide qui tend à détruire l'instabilité supraconductrice au profit de la phase magnétique en concurrence. Sous faible pression hydrostatique la phase magnétique n'est plus observée.

Abstract. - A magnetic state is observed below $\sim 3.5 \mathrm{~K}$ in the organic superconductor (TMTSF) $)_{2} \mathrm{ClO}_{4}$ just above the superconducting transition $\left(T_{\mathrm{c}} \sim 1 \mathrm{~K}\right)$. This state is obtained by fast cooling with a rate of $\sim 25 \mathrm{~K} / \mathrm{min}$. and evidenced by ${ }^{77} \mathrm{Se}$ and ${ }^{1} \mathrm{H}-\mathrm{NMR}$ intensity and relaxation measurements. The onset temperature is nearly field-independent between 10 and $65 \mathrm{kOe}$. In the same sample, slow cooling suppresses the magnetism to at least below $1.3 \mathrm{~K}$. The heat cycle effects are fully reproducible. The results imply that fast cooling freezes in lattice disorder which depresses superconductivity and therefore leave room for the competing magnetic phase. A small hydrostatic pressure also depresses the magnetism.
\end{abstract}

1. Introduction. - An important feature of the family of pseudo one-dimensional organic conductors (TMTSF $)_{2} \mathrm{X}(\mathrm{X}=$ univalent anion) is the competition between two types of critical behaviour at low temperatures [1]. In salts where $\mathrm{X}$ is an anion possessing inversion symmetry $\left(\mathrm{X}=\mathrm{PF}_{6}, \mathrm{AsF}_{6}, \mathrm{SbF}_{6}, \mathrm{TaF}_{6}, \mathrm{NbF}_{6}, \mathrm{etc}\right.$.) an overwhelming amount of evidence has demonstrated that the metal to insulator transition in the $11-18 \mathrm{~K}$ region is a transition into a magnetic state, a so-called spin density wave(SDW) state [2-6]. Under pressure the magnetic transition is gradually depressed and above a critical pressure of about 8 kbar a 3-D ordered superconducting (SC) state is established below about $1 \mathrm{~K}$ [7-11]. An additional result of the pressure investigations is

$\left(^{*}\right)$ IUPAC name : $\mathrm{Di}-\left(\Delta^{2,2}\right.$-bi-4,5-dimethyl-1,3-diselenolylidene) ium-perchlorate.

$(* *)$ Permanent address : H. C. Oersted Institute, Universitetsparken 5, DK-2100, Copenhagen, Denmark. 
the coexistence region of SDW and SC, as indicated by an upturn in resistivity before the onset of superconductivity at pressures (for (TMTSF) ${ }_{2} \mathrm{PF}_{6}$ ) between 6.5 and about $8 \mathrm{kbar}$ [12].

When $\mathrm{X}$ is a non-centrosymmetric anion $\left(\mathrm{X}=\mathrm{ClO}_{4}\right.$ and $\left.\mathrm{ReO}_{4}\right)$, the situation is further complicated. (TMTSF) ${ }_{2} \mathrm{ReO}_{4}$ exhibits an order-disorder transition (the anions order with $2 k_{\mathrm{F}}$ periodicity) at $180 \mathrm{~K}$ leading to an insulating non-magnetic state at ambient pressure [13, 14]. (TMTSF) ${ }_{2} \mathrm{ClO}_{4}$ is so far the only material that exhibits the 3-D ordered superconducting state already at ambient pressure, as demonstrated by zero-resistance [15] and Meissner effect [16]. The lack of a SDW state in this material was originally ascribed to a disordered anion lattice $[15,14,17]$.

The experimental situation for (TMTSF) ${ }_{2} \mathrm{ClO}_{4}$ is more complex than that for (TMTSF) ${ }_{2} \mathrm{PF}_{6}$ and similar anion types. Various groups report different transition temperatures [18] and even here, the upturn in resistivity [19,11], the decrease of the EPR intensity [20] and evidence for antiferromagnetic resonance [21] indicate an onset of a SDW state and possible coexistence of SDW and SC slightly above the SC transition. Recently specific heat measurements [22] detected the SC state and also revealed that the application of a magnetic field of $63 \mathrm{kOe}$ along $c^{*}$ axis restores a state exhibiting a low density of states at the Fermi level below $1.4 \mathrm{~K}$. Additional evidence for the semimetallic nature of this magnetically induced phase comes from an observation of Shubnikov-de Haas oscillations with a similar onset field [23]. A similar high-field phase transition in (TMTSF) ${ }_{2} \mathrm{PF}_{6}$ has also been observed by ${ }^{1} \mathrm{H}-\mathrm{NMR}$ relaxation [24] and Shubnikovde Haas measurements [25] at $P \geqslant 6.5$ kbar.

We report clear evidence $\left({ }^{1} \mathrm{H}\right.$ and $\left.{ }^{77} \mathrm{Se}-\mathrm{NMR}\right)$ that a magnetic state can be induced in much lower field below $\sim 3.5 \mathrm{~K}$ by fast cooling below $40 \mathrm{~K}$ (Quenched State), and that the transition temperature is field-independent, whereas we failed to observe a magnetic transition in slowly cooled samples (Relaxed State) within our experimental possibilities : $H<65 \mathrm{kOe}$ and $T>1.3 \mathrm{~K}$. The quenching process is fully reproducible.

2. Experimental. - A single crystal of $(\mathrm{TMTSF})_{2} \mathrm{ClO}_{4}[20]\left(0.5 \times 0.5 \times 3.0 \mathrm{~mm}^{3}\right)$ was used for ${ }^{77} \mathrm{Se}$ and ${ }^{1} \mathrm{H}$-NMR at ambient pressure. A home-made pulsed NMR spectrometer with a crossed-coil probe was operated at frequencies of 45 and $53 \mathrm{MHz}$. The receiver coil is rectangular with a size of $\left(0.7 \times 0.8 \times 3 \mathrm{~mm}^{3}\right)$ in order to improve the filling factor. The transmitter coil is a Helmholtz-type with an inner diameter of $5 \mathrm{~mm}$. The ${ }^{77} \mathrm{Se}$ spin echo signal following $\pi / 2-\pi$ pulse series was accumulated by a differential analog box-car integrator and the NMR absorption line was observed by a field sweep method. For ${ }^{1} \mathrm{H}-\mathrm{NMR}$ the free induction signal, following the $\pi / 2$ pulse, was sampled digitally on a transient recorder and analysed with a microcomputer. The spinlattice relaxation time was obtained by measuring the time-recovery after a saturation combpulse. All single crystal measurements reported were obtained with the external magnetic field parallel to $c^{*}$, the lowest $H_{\mathbf{c}_{2}}^{\perp}$ axis $[26,27]$. The $3 \mathrm{kbar}$ measurements were performed on a powdered sample $(20 \mathrm{mg})$ using a single-coil probe.

3. Results - Figure 1 displays the temperature dependence of the ${ }^{77}$ Se-NMR intensity obtained after fast cooling below $50 \mathrm{~K}$ at a rate greater than $20 \mathrm{~K} / \mathrm{min}$. The relative intensity is calculated as the signal amplitude multiplied by the linewidth, since the observed line-shape is a symmetric Gaussian apart from a possible long tail below the noise level. At temperatures well above $\sim 5 \mathrm{~K}$, the linewidth gradually increases as the temperature decreases, but the intensity $I$ follows a Curie law $\left(I . T=\right.$ const.). Thus the number of ${ }^{77} \mathrm{Se}$ nuclei contributing to the signal appears constant. Below $5 \mathrm{~K}$, the linewidth continues to increase and the signal amplitude now decreases rapidly, thus the apparent intensity is reduced. There appears to be no appreciable change in the resonance field of this residual signal. These features are similar to those observed for the magnetic transition of (TMTSF) ${ }_{2} \mathrm{PF}_{6}$ at ambient pressure [5]. Because the ${ }^{77}$ Se nucleus has $I=1 / 2$, there is no doubt that the reduction of the signal intensity is caused by the inhomogeneous large shift (or broadening) of the resonance due to an onset of a strong local field of hyperfine origin. 


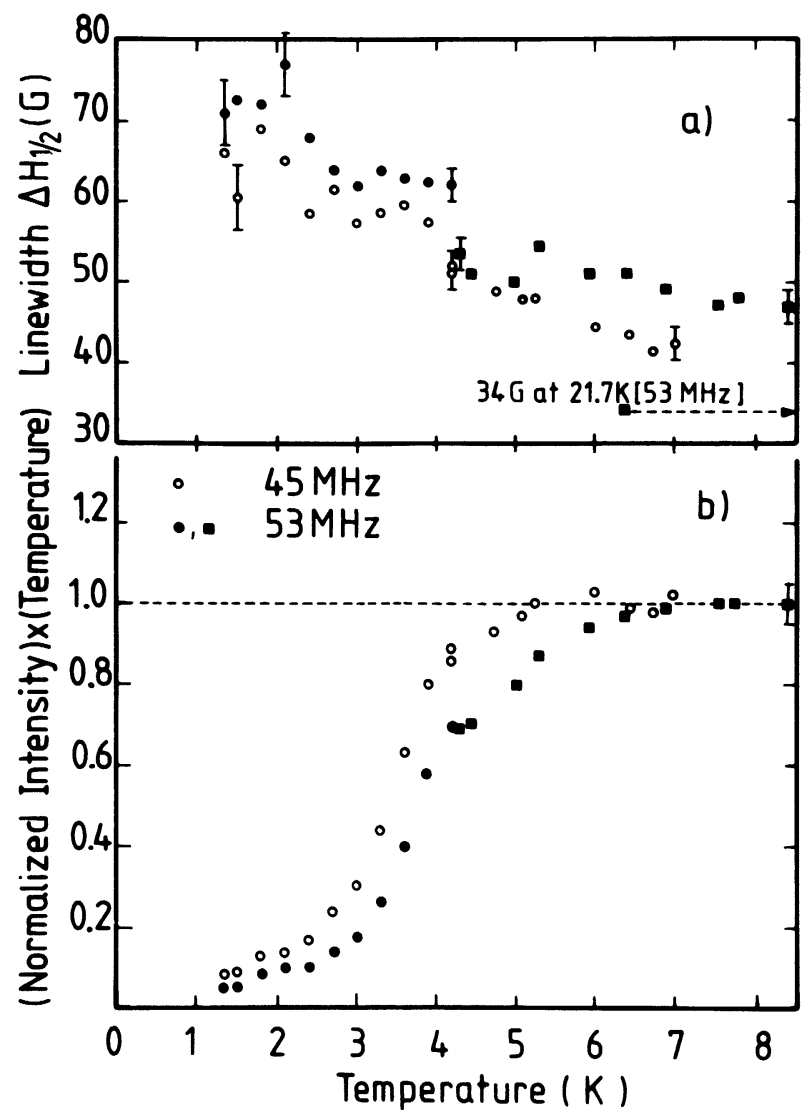

Fig. 1. - Temperature dependence of the ${ }^{77}$ Se-NMR signal intensity and linewidth at $45 \mathrm{MHz}$ and $53 \mathrm{MHz}$. (a) Full width at half maximum of the absorption line. The linewidth at $21.7 \mathrm{~K}$ is also indicated. (b) Reduction of the signal intensity. The $y$-axis indicates the normalized amplitude multiplied by temperature. The straight dashed line indicates Curie law behaviour.

Figure 2 shows the spin-lattice relaxation rate $T_{1}^{-1}$ of ${ }^{77} \mathrm{Se}$ at $53 \mathrm{MHz}$ together with the reduction of the intensity. The relaxation rate displays a sharp peak at the same temperature where the decrease in intensity occurs.

The data presented in figures 1 and 2 give evidence for a phase transition at $T_{\mathrm{M}}$ around $3.5 \mathrm{~K}$ in a magnetic field of $65 \mathrm{kOe}$ along the $c^{*}$ axis. The low temperature phase is clearly magnetic (SDW) as shown by the occurrence of an internal magnetic field and a spin-lattice relaxation peak related to the critical slowing-down of magnetic fluctuations at the phase transition. We notice that the transition region is much broader than in the case of (TMTSF) ${ }_{2} \mathrm{PF}_{6}$ at ambient pressure [5].

Another important result is the remarkable dependence of the magnetic transition on the cooling process. This effect made systematic measurements quite difficult. After repeated heat cycles on the same crystal, as shown in figure 3, we found some tendencies as follows :

1) The « quenched » state obtained by fast cooling after keeping the sample at a high temperature has a high $T_{M}$ (defined here as the temperature of the half height in the $I$. $T$-plot). The highest $T_{M} \sim 3.7 \mathrm{~K}$ was obtained with a cooling rate of $-25 \mathrm{~K} / \mathrm{min}$. and an initial temperature of $55 \mathrm{~K}$ (run 4 in Fig. 3). 


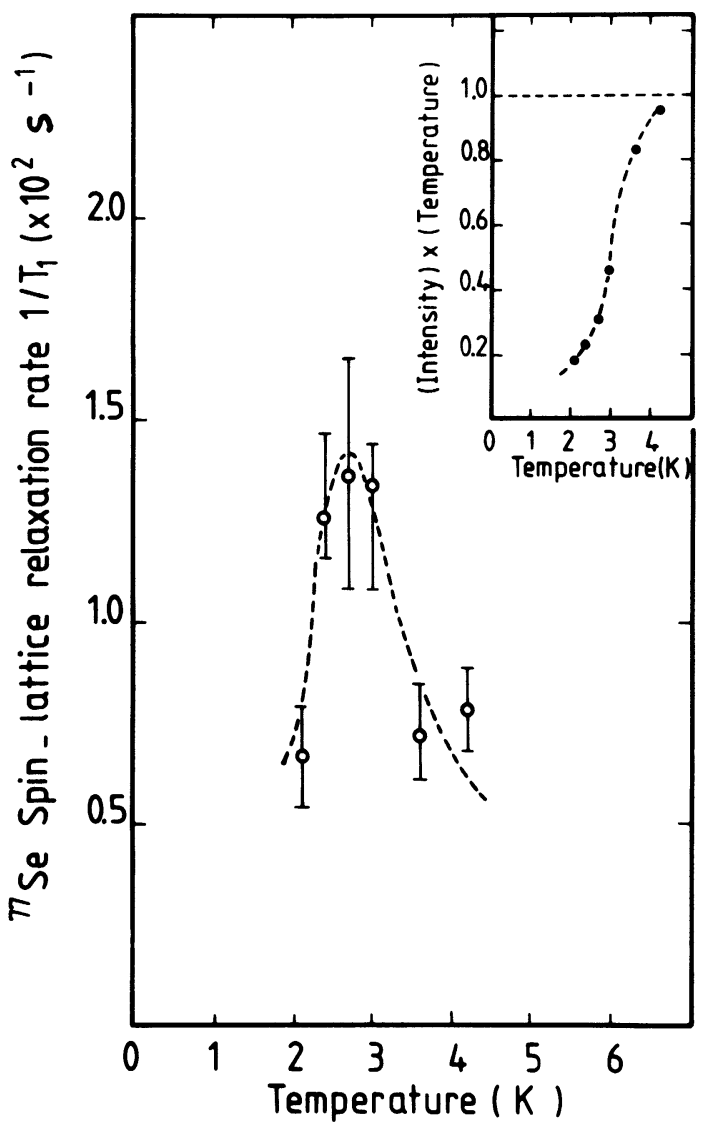

Fig. $2 .-{ }^{77}$ Se spin-lattice relaxation rate versus temperature. Insert shows the reduction of signal intensity measured in the same run. The line is a guide to the eye.

ii) The "quenched" state can be annealed around $T \sim 20 \mathrm{~K}$. The sample annealed at this temperature for several hours does not show the expected reduction of intensity down to $1.37 \mathrm{~K}$ (run 1 in Fig. 3), but the beginning of the line broadening $\left(\Delta H_{1 / 2} \sim 61 \mathrm{G}\right.$ at $\left.1.37 \mathrm{~K}\right)$ suggests the existence of the transition at a lower temperature. Run 2 is an example of a partially annealed case.

iii) The heat cycle effects are reproducible. After run 1, the sample was warmed up to $50 \mathrm{~K}$, kept at this temperature for $30 \mathrm{~min}$. and then cooled down to $4.2 \mathrm{~K}$ by similar fast cooling. The magnetic transition temperature increased again (run 3 in Fig. 3).

iv) The magnetic state is rather stable if the sample is held below $4.2 \mathrm{~K}$. The drift of the transition temperature is estimated to be less than $0.1 \mathrm{~K}$ after 2 days.

As is already mentioned, there are discrepancies between the experimental results concerning the two types of instabilities : SDW and SC in (TMTSF) ${ }_{2} \mathrm{ClO}_{4}$. The present observations clearly show that the cooling process affects the competition between the SDW and SC instability, at least, at ambient pressure. In the specific heat measurement in zero-field, the 3-D superconducting transition temperature was observed to be depressed to $T_{\mathrm{c}} \sim 0.9 \mathrm{~K}$ by a similar fast cooling process $[22,28]$.

The dependence on the external field of this magnetic transition in the " quenched " state was found to be small by ${ }^{77} \mathrm{Se}-\mathrm{NMR}$ measurements at $53 \mathrm{MHz}$ and $45 \mathrm{MHz}$ (which correspond to external fields of $65 \mathrm{kOe}$ and $55 \mathrm{kOe}$, respectively). Figure 1 shows that the transition temperature 


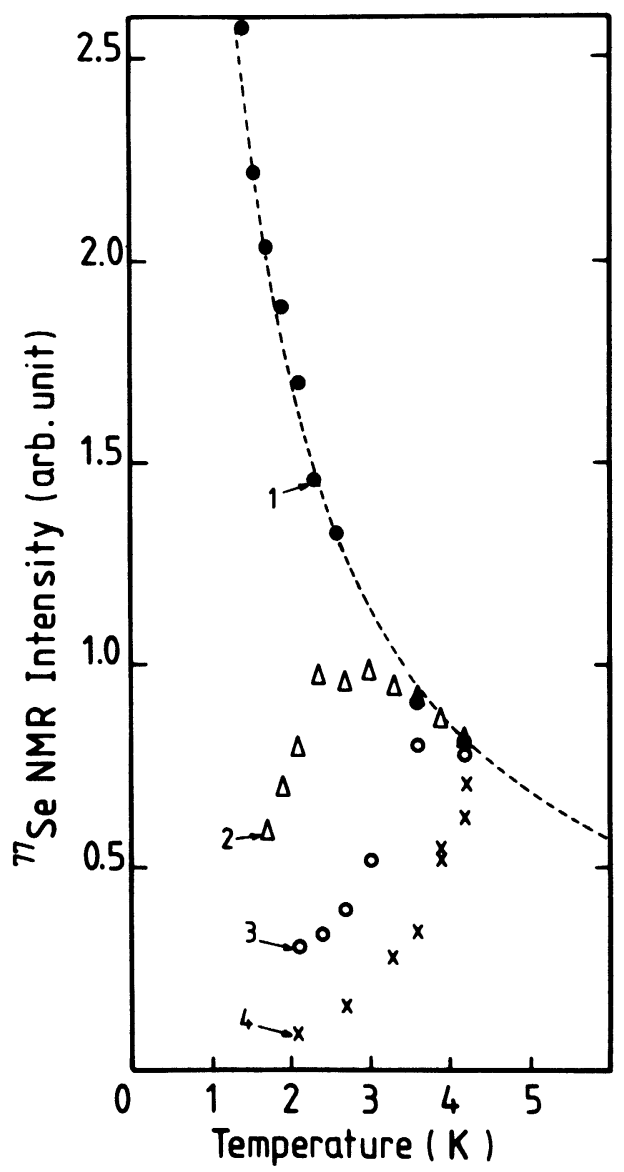

Fig. 3. - Heat cycle effect on the magnetic transition in the same sample. The NMR signal intensity below $4.2 \mathrm{~K}$ is plotted against temperature for different cooling processes (see text). The dashed curve indicates Curie law behaviour.

at $55 \mathrm{kOe}$ is $\sim 0.4 \mathrm{~K}$ lower than at $65 \mathrm{kOe}$. However we cannot eliminate the possible ambiguity due to the normalization process and/or the unexpected annealing effects.

The magnetic phase transition is also observed by ${ }^{1} \mathrm{H}-\mathrm{NMR}$ at $45 \mathrm{MHz}$ in a field of $10.6 \mathrm{kOe}$. The ${ }^{1} \mathrm{H}$ spin-lattice relaxation rate has a sharp peak at low temperature as shown in figure 4 . Defining the transition temperature as the peak position, $T_{\mathrm{M}}$ at $10.6 \mathrm{kOe}$ in the " quenched " state is $3.6 \mathrm{~K}$, which is almost the same as found by ${ }^{77} \mathrm{Se}-\mathrm{NMR}$ at higher fields. The linewidth of the ${ }^{1} \mathrm{H}-\mathrm{NMR}$ absorption increases by $25 \mathrm{G}$ below the transition temperature. A clear annealing effect is also observed : the transition temperature decreases by $0.6 \mathrm{~K}$ after annealing at $10-12 \mathrm{~K}$ for 3 hours. An extremely slow cooling from $40 \mathrm{~K}$ with a cooling rate $<0.2 \mathrm{~K} / \mathrm{min}$. depressed the magnetic transition at least below $1.2 \mathrm{~K}$, which is the experimental limit of the present work.

Hydrostatic pressure was found to "relax " the sample, as shown in figure 5. At ambient pressure, the ${ }^{1} \mathrm{H}$ relaxation in the powdered sample shows a non-single exponential behaviour below $7 \mathrm{~K}$ and the initial slope of the relaxation curve increases as the temperature decreases. The non-single exponential behaviour can be attributed to the inhomogeneity of the relaxation rate due to random orientations, and the rapid increase of the initial slope corresponds to the relaxation peak observed in the single crystal. By applying a pressure of $3 \mathrm{kbar}$, the relaxation of ${ }^{1} \mathrm{H}$ is 


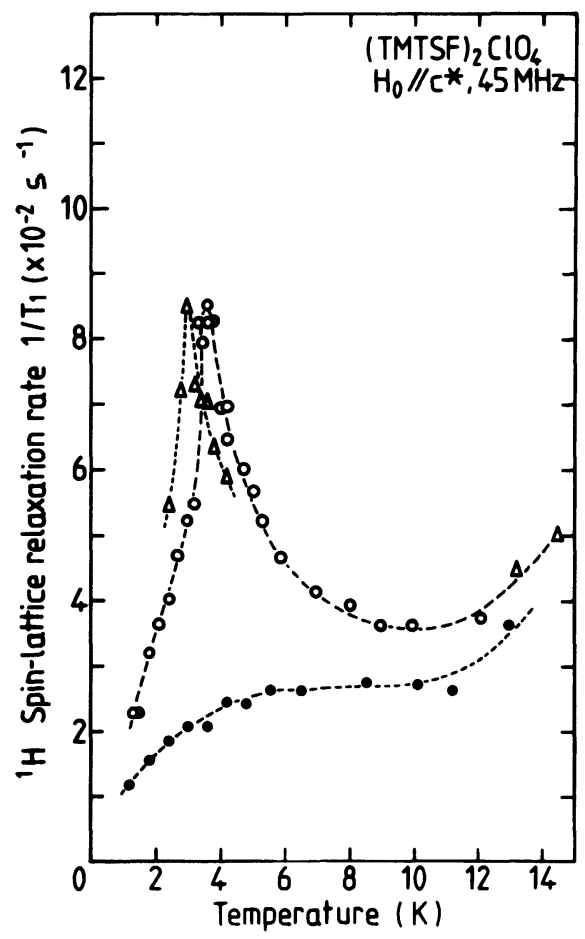

Fig. 4. - ${ }^{1} \mathrm{H}$ spin-lattice relaxation rate versus temperature in the " quenched " state (O), in the partially annealed state $(\triangle)$ and in the « relaxed " state $(\bullet)$. The cooling conditions are given in the text.

depressed down to the values observed in the single crystal in the « relaxed » state. Below $6 \mathrm{~K}$, the relaxation is still non-single exponential, but no rapid component was observed. This indicates that the magnetic phase in the " quenched " state can be suppressed by applying a pressure of $3 \mathrm{kbar}$, and is in agreement with the results that the upturn of the resistance of (TMTSF) ${ }_{2} \mathrm{ClO}_{4}$ is also suppressed by the same pressure [11].

4. Discussion. - The present experiments clearly point to the necessity of distinguishing two different low temperature states of (TMTSF) ${ }_{2} \mathrm{ClO}_{4}$; the " quenched " state (Q-state) obtained by fast cooling below $40 \mathrm{~K}$ and the " relaxed " state (R-state) obtained by slow cooling. The Q-state has a magnetic phase transition at $T_{\mathrm{M}} \sim 3.5 \mathrm{~K}$ and the transition temperature is nearly fieldindependent up to $65 \mathrm{kOe}$. The observation of the upturn in the resistivity in the low temperature region $[11,19]$ and the antiferromagnetic resonance at $1.4 \mathrm{~K}[21]$ in $(\mathrm{TMTSF})_{2} \mathrm{ClO}_{4}$ is probably related to this magnetic phase. In this state, the 3-D superconducting transition in zero-field occurs at $T_{c} \sim 0.9 \mathrm{~K}$, as observed by the specific heat measurement [28]. Thus the Q-state of $(\mathrm{TMTSF})_{2} \mathrm{ClO}_{4}$ in zero-field appears similar to (TMTSF) ${ }_{2} \mathrm{PF}_{6}$ at a pressure just below the critical pressure ( $\sim 8 \mathrm{kbar})$, where successive transitions of SDW and SC appear [12]. This picture is consistent with the result that the application of a pressure of $3 \mathrm{kbar}$ depresses the magnetic transition at least below $1.2 \mathrm{~K}$. The proposed $T-H$ phase diagram for the Q-state at ambient pressure is shown in figure $6 a$.

In the R-state, there is no magnetic transition in the region of $10 \mathrm{kOe}<H_{0}<65 \mathrm{kOe}$ and $T>1.37 \mathrm{~K}$. The 3-D superconducting transition temperature in the zero-field is $T_{\mathrm{c}} \sim 1.2 \mathrm{~K}$ $[15,18,22]$. In the higher field region, there appears to be a " semimetallic " phase induced by a strong magnetic field, as indicated by the specific heat measurement in a field of $63 \mathrm{kOe}$ [22] and 


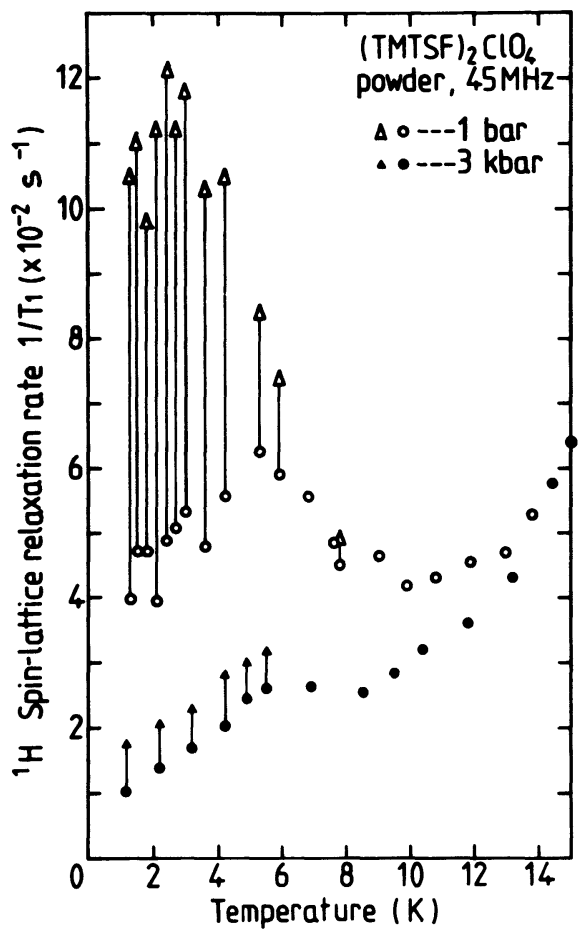

Fig. 5. $-{ }^{1} \mathrm{H}$ spin-lattice relaxation rate in the "quenched " state of the powdered sample, at ambient pressure (0) and at $3 \mathrm{kbar}(0)$. The cooling rate below $40 \mathrm{~K}$ is $\sim 20 \mathrm{~K} / \mathrm{min}$. in both cases. The non-single exponential behaviour observed below $7 \mathrm{~K}$ is indicated by a line connecting the initial slope $(\Delta, \Delta)$ and the main component $(0, \bullet)$ to which more than $60 \%$ of the total intensity contributes.

the existence of a threshold for the Shubnikov-de Haas oscillation [23]. This suggests a $T-H$ phase diagram for the R-state as shown in figure $6 b$. The present measurements are not complete in the sense that only the region $T>1.2 \mathrm{~K}$ was investigated, but we expect that this high-field phase is a magnetic phase (SDW). In order to clarify this, measurements of the precise field dependence at $T<1.2 \mathrm{~K}$ are necessary.

The origin of the heat cycle effects is so far not well understood. EPR measurements under carefully controlled heat cycles, which are now going on [29], can probably disclose the temperature region and maximum cooling rate necessary to obtain the R-state. Obviously, the quenching effects are not caused by crystal damage, such as " microcracks ", but related to a yet unclarified lattice instability. We now propose a model of the quenching phenomena in terms of lattice disorder.

(TMTSF) ${ }_{2} \mathrm{ClO}_{4}$ crystallizes in the triclinic unit cell $\mathrm{P} \overline{1}$. The inversion centres at the origin, are at high temperatures obtained by the tetrahedral $\mathrm{ClO}_{4}$ occupying two equivalent positions statistically $[20,30]$. In the similar(TMTSF) ${ }_{2} \mathrm{ReO}_{4}$ the $\mathrm{ReO}_{4}$ order at $180 \mathrm{~K}$ with a new periodicity $(2 a, 2 b, 2 c)$ in $\mathbf{P} \overline{1}$ [14]. This creates a gap at the Fermi level. In (TMTSF) ${ }_{2} \mathrm{ClO}_{4}, \mathrm{X}$-ray data have failed to detect a similar ordering down to below $15 \mathrm{~K}$ [14]. We suggest however that ordering of the $\mathrm{ClO}_{4}$ can occur with another periodicity $(a, b, c)$, corresponding to a transition from $\mathrm{P} \overline{1}$ to $\mathrm{P} 1$ (ferroelectric order). To a first approximation this should not affect the density of states severely. If the quenching below $40 \mathrm{~K}$ freezes in some of the statistical disorder present at high temperatures, a small disorder potential is introduced along the conducting stack. Following the explanation of 


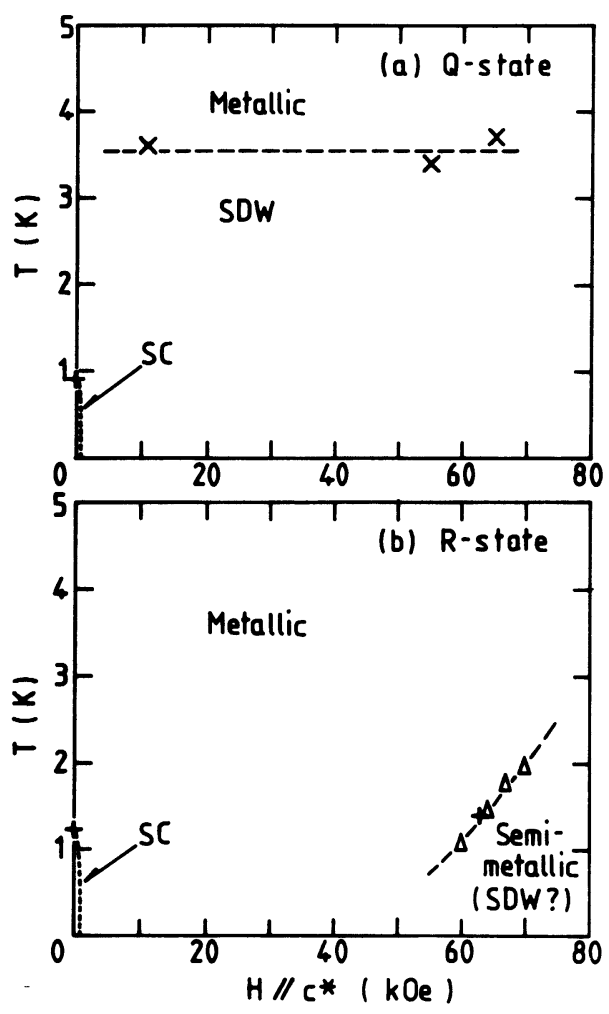

Fig. 6. - Proposed ( $T$ versus $H$ ) phase diagram, $(a)$ for the " quenched " state and $(b)$ for the "relaxed " state. The results of specific heat measurement (+, Ref. [22]) and the onset of Shubnikov-de Haas oscillations $(\triangle$, Ref. [23]) are included.

Larkin et al. [31], the disorder potential can suppress the superconductivity and leave room for the onset of the SDW state. We have admittedly no direct evidence (structural) for this suggestion but several pieces of indirect evidence.

i) Ferroelectric ordering lowers the energy of the naked anion lattice [13].

ii) Recent specific heat measurements show that the SC transition is depressed by the quenching process from $1.2 \mathrm{~K}$ to $0.9 \mathrm{~K}$ and simultaneously show excess entropy, indicating that the quenched state is disordered [26]. Similarly the introduction of a disorder potential by doping (TMTSF) ${ }_{2} \mathrm{ClO}_{4}$ with $\mathrm{ReO}_{4}$ completely suppresses the superconductivity to at least below $50 \mathrm{mK}$ [32] even although a metallic and highly conducting state is obtained by a pressure of about $3 \mathrm{kbar}$.

iii) Finally the relatively high annealing temperature $(T>20 \mathrm{~K})$ also implies that the lattice rearranges.

In résumé we suggest that in the quenched state of (TMTSF) ${ }_{2} \mathrm{ClO}_{4}$ disorder depresses the $\mathrm{SC}$ instability and therefore the SDW phase can occur. We emphasize that this situation is different from that in (TMTSF) ${ }_{2} \mathrm{PF}_{6}$ where $\mathrm{PF}_{6}$ has inherent inversion symmetry and 1 bar is far below the critical pressure for suppression of the SDW phase.

Acknowledgments. - We thank H. J. Schulz and C. Bourbonnais for fruitful discussions and C. Andrzejewski and A. Andrieux for skilful technical assistance. The continued communication with R. Brusetti and S. Tomic is greatly appreciated. 


\section{References}

[1] Recent experimental results are contained in : Proceedings of the International Conference on LowDimensional Conductors, Boulder (1981) in Mol. Cryst. Liq. Cryst. 79 (1982). See also a review by FrIEDEL, J. and Jérome, D., to be published in Contemporary Physics (1982).

[2] Mortensen, K., Tomkiewicz, Y., SChultz, T. D. and Engler, E. M., Phys. Rev. Lett. 46 (1981) 1234.

[3] Scott, J. C., Pedersen, H. J. and Bechgand, K., Phys. Rev. Lett. 45 (1980) 2125.

[4] Walsh Jr., W. M., Wudl, F., Thomas, G. A., Nalewajek, D., Hausser, J. J., Lee, P. A. and Poehler, T., Phys. Rev. Lett. 45 (1980) 829.

[5] AndrieuX, A., Jérome, D. and BechgaArd, K., J. Physique-Lett. 42 (1981) L-87.

[6] Torrance, J. B., Pedersen, H. J. and Bechgaard, K., preprint and Bull. Am. Phys. Soc. 27 (1982) 150.

[7] Jérome, D., Mazaud, A., Ribault, M. and Bechgaard, K., Phys. Lett. 41 (1981) L-95.

[8] Ribault, M., Benedex, G., Jérome, D. and Bechgaard, K., J. Physique-Lett. 41 (1980) L-397.

[9] Andres, K., Wudl, F., McWhan, D. B., Thomas, G. A., Nalewajek, D. and Stevens, A. L., Phys. Rev. Lett. 45 (1980) 1449.

[10] Schulz, H. J., Jérome, D., Ribault, M., Mazaud, A. and BechgaArd, K., J. Physique-Lett. 42 (1981) L-51.

[11] Parkin, S. S. P., Ribault, M., Jérome, D. and Bechgaard, K., J. Phys. C 14 (1981) 5305.

[12] Greene, R. L. and Engler, E. M., Phys. Rev. Lett. 45 (1980) 1587.

[13] Jacobsen, C. S., Pedersen, H. J., Mortensen, K., Rindorf, G., Thorup, N., Torrance, J. B. and BechgaArd, K., to be published in J. Phys. C (1982).

[14] Pouget, J. P., Moret, R., Comes, R., Bechgaard, K., Fabre, J. M. and Giral, L., Mol. Cryst. Liq. Cryst. 79 (1982) 129.

[15] Bechgaard, K., Carneiro, K., Olsen, M., Rasmussen, F. B. and Jacobsen, C. S., Phys. Rev. Lett. 46 (1981) 852.

[16] Schwenk, H. Neumaier, K., Andres, K., Wudl, F. and Aharon-Shalom, E., Mol. Cryst. Liq. Cryst. 79 (1982) 277.

[17] BechgaARD, K., Mol. Cryst. 79 (1982) 1.

[18] Bechgaard, K., Carneiro, K., Eg, O., Olsen, M., Rasmussen, F. B., Jacobsen, C. S. and Rindorf, G., Mol. Cryst. Liq. Cryst. 79 (1982) 271.

[19] Murata, K., Ukachi, T., Anzai, H., Saito, G., Kajimura, K. and Ishiguro, T., J. Phys. Soc. Japan 51 (1982) 1825.

[20] Bechgaard, K., Carneiro, K., Rasmussen, F. B., Olsen, M., Rindorf, G., Jacobsen, C. S., Pedersen, H. and ScotT, J. C., J. Am. Chem. Soc. 103 (1981) 2440.

[21] Walsh Jr., W. H., Bull. Am. Phys. Soc. 27 (1982) 150.

[22] Garoche, P., Brusetti, R., Jérome, D. and Bechgaard, K., J. Physique-Lett. 43 (1982) L-147.

[23] KwaK, J. E., Schirber, J. E., Greene, R. L. and Engler, E. M., Mol. Cryst. Liq. Cryst. 79 (1982) 111.

[24] Azevedo, L. J., Schirber, J. E., Greene, R. L. and Engler, E. M., Physica 108B (1981) 1183.

[25] Kwak, J. E., Schirber, J. E., Greene, R. L. and Engler, E. M., Phys. Rev. Lett. 46 (1981) 1296.

[26] Greene, R. L., Haen, P., Huang, S. Z., Engler, E. M., Choi, M. Y. and Chaikin, P. M., Mol. Cryst. Liq. Cryst. 79 (1982) 183.

[27] Murata, K., Anzai, H., Kajimura, K., Ishiguro, T. and Saito, G., Mol. Cryst. Liq. Cryst. 79 (1982) 283.

[28] Garoche, P., Brusetti, R. and BechgaARD, K., to be published.

[29] Tомić, S., et al., to be published.

[30] ThORup, N., Rindorf, G., Soling, H. and BechgaArd, K., Acta Crystallogr. B 37 (1981) 1236.

[31] Larkin, A. I. and Mel'Nikov, V. I., Sov. Phys. JETP 44 (1976) 1159.

[32] Tomić, S., et al., to be published. 